\title{
The marine intertidal zone shapes oyster and clam digestive bacterial microbiota
}

\author{
Offret Clement ${ }^{1}$, Paulino Sauvann ${ }^{1}$, Gauthier Olivier ${ }^{1}$, Château Kevin ${ }^{1}$, Bidault Adeline ${ }^{1}$, \\ Corporeau Charlotte 2, Miner Philippe 2, Petton Bruno 2, Pernet Fabrice 2, Fabioux Caroline ${ }^{1}$, \\ Paillard Christine ${ }^{1}$, Le Blay Gwenaelle ${ }^{1, *}$
}

1 Univ Brest, CNRS, IRD, Ifremer, LEMAR, F-29280 Plouzané, France

2 Ifremer, Univ Brest, CNRS, IRD, LEMAR, F-29280 Plouzané, France

* Corresponding author : Gwenaelle Le Blay, email address : gwenaelle.leblay@univ-brest.fr

\begin{abstract}
:
Digestive microbiota provides a wide range of beneficial effects on host physiology and are therefore likely to play a key role in marine intertidal bivalve ability to acclimatize to the intertidal zone. This study investigated the effect of intertidal levels on the digestive bacterial microbiota of oysters Crassostrea gigas and clams Ruditapes philippinarum, two bivalves with different ecological niches. Based on the 16S rRNA region sequencing, digestive glands, seawater and sediments harbored specific bacterial communities, dominated by OTUs assigned to the Mycoplasmatales, Desulfobacterales and Rhodobacterales orders, respectively. Field implantation modified digestive bacterial microbiota of both bivalve species according to their intertidal position. Rhodospirillales and Legionellales abundances increased in oysters and clams from low intertidal level, respectively. After a 14-day depuration process, these effects were still observed especially for clams, while digestive bacterial microbiota of oysters were more subjected to short-term environmental changes. Nevertheless, 3.5 months stay on intertidal zone was enough to leave an environmental footprint on the digestive bacterial microbiota, suggesting the existence of autochthonous bivalve bacteria. When comparing clams from the three intertidal levels, $20 \%$ of the bacterial assemblage was shared among the levels and it was dominated by OTU affiliated to the Mycoplasmataceae and Spirochaetaceae families.
\end{abstract}

Keywords : microbiota, oysters, clams, intertidal zone, digestive gland, metabarcoding 


\section{INTRODUCTION}

Host-associated microbiota play a key role in host homeostasis and health, by (i) promoting development (McFall-Ngai 2002), (ii) providing protection against pathogens (Offret et al. 2018) and/or (iii) improving adaptation to environmental modifications (Torda et al. 2017). It is hypothesized that microbiota modification may strongly impact its host in terms of physiology, immunology and nutrient uptake (McFallNgai et al. 2013; Baker et al. 2018; Clerissi et al. 2018; Dubé et al. 2019). Host-associated microbiota consist of more or less complex communities of microorganisms, some of which are more adapted to their host, others generalist, or transient, representing a wide range of potential contributions (Shapira 2017). It is well known that bivalves harbor their own microbiota (as for other organisms), whose characteristics and functions are still poorly understood, but cannot be ignored (Desriac et al. 2014; Offret et al. 2019).

Microbial community composition and diversity associated with oysters (Trabal et al. 2012; Trabal Fernández et al. 2014; King et al. 2019b) and clams (Romalde et al. 2013; Meisterhans et al. 2015) are beginning to be described with culture-independent methods from different tissues, such as hemolymph (Lokmer and Wegner 2014; Lokmer et al. 2016b, 2016a), mantle (Lokmer et al. 2016b; King et al. 2020), gills (Wegner et al. 2013; Lokmer et al. 2016b; King et al. 2020), adductor muscle (King et al. 2019c, 2020) or digestive gland (King et al. 2012, 2019a, 2020; Lokmer et al. 2016b; Milan et al. 2018; Vezzulli et al. 2018). The digestive gland (DG) is one of the most colonized tissue of bivalves with the highest concentrations of bacteria (Kueh and Chan 1985). Digestive microbiota generally supplies the host with exogenous nutrients and extracellular enzymes, fatty acids and vitamins (Dhanasiri et al. 2011), thus contributing to nutrient degradation and uptake (Harris 1993; Simon et al. 2019). The establishment and structuring of the DG microbiota depend on physiological, genetic and immune characteristics of the host, the environment, the type of food ingested, as well as the interactions between microorganisms (Hacquard and Schadt 2015). For that reason, structuring of DG microbiota may play a key role in the metabolic condition of bivalves by influencing their growth capacity, immunity, energy load, nutrition process and digestive enzyme activities (Harris 1993; Rőszer 2014).

Microbiota structuration and composition are affected by both host and habitat factors (Kvennefors et al. 2010), such as intertidal position. Marine intertidal zones represent a heterogeneous environment (Harley et al. 2006) structured by different gradients of biotic and abiotic factors including temperature, salinity, nutrients, UV and rainfall variations (Connell 1972; Helmuth and Hofmann 2001). Marine organisms are facing different physiological challenges based on their position within the intertidal zone, which further result in physiological differences (Soudant et al. 2004; Fernández-Reiriz, Irisarri and Labarta 2016; Yin et al. 
2017). The Pacific oyster, Crassostrea gigas, and the Manilla clam, Ruditapes philippinarum, are epifaunal and infaunal bivalves, respectively, with important economic value worldwide. Both species are subject to different biotic and abiotic factors due to their distribution within the marine tidal zone. Oysters living in the intertidal zone, attach and feed on planktonic microalgae, while clams burrowing in sediment mainly ingest benthic microalgae and sedimented phytoplankton (Simons et al. 2018). To date, previous studies have shown that the oyster microbiota could change under a multitude of different stressful treatments, such as translocation, starvation, temperature, infection and antibiotic treatment (Green and Barnes 2010; Wegner et al. 2013; Lokmer and Wegner 2014; Lokmer et al. 2016b, 2016a; Green et al. 2019). However, to our knowledge no study has ever investigated the effect of different intertidal levels on bivalve microbiota along a transect between the upper and lower limits of their distribution from shore. The aim of this study was to investigate consequences of intertidal position on DG microbiota in two bivalve species with different ecology, the Pacific oyster C. gigas and the Manilla clam R. philippinarum. To this end, individuals of both species were deployed at one site in the Bay of Brest (Brittany, France) at three contrasted intertidal levels (high, middle and low) for 3.5 months. Bacterial microbiota from the DG were explored for composition and structuration by metabarcoding analysis. To evaluate the environmental footprint on the DG microbiota, a cohort of bivalves was placed in depurated conditions to analyze the intertidal level-specific microbiota that remains in the animals.

\section{MATERIALS AND METHODS}

\section{Biological samples}

C. gigas oysters' families were produced in February 2017 using a developed methodology that allowed the production of pathogen-free juveniles, called "Naissain Standardisé Ifremer" (NSI). In larval and post-larval stages, the oysters were maintained in controlled condition at the laboratory (Argenton, France). The clams R. philippinarum were provided by a commercial exploitation (SATMAR, France). They were descendants of clams families (around 1000 families) born in April 2016. Before deployment in the field, mean shell length was $47.1 \pm 5.2 \mathrm{~mm}$ for oysters and $20.3 \pm 2.3 \mathrm{~mm}$ for clams.

\section{Experimental design on intertidal site}

Oysters and clams were transferred in mid-October 2017 to a farming area (surface of ca. $200 \mathrm{~m}^{2}$ ) located in the Bay of Brest at Pointe du Chateau (48 $20^{\prime} 06.19^{\prime \prime} \mathrm{N}, 4^{\circ} 19^{\prime} 06.37^{\prime \prime}$ W, Britany, France). The chosen implantation period (water temperature $<16^{\circ} \mathrm{C}$ ) is a period without oyster mortality events (Petton et al. 2015), without phytoplanktonic bloom (Lessin et al. 2019), with low growth rates (Menzel 2018) and no 
breeding, which facilitated access to the DG. Animals were deployed at three rearing heights $(1,2.8$ and 4 meters above sea level) corresponding to $20 \%, 56 \%$ and $80 \%$ of exondation time (Fig. 1). Similar to cultivation practices, animals were placed in two duplicated mesh bags of 190 individuals for oysters $(2 \times 190$ $=380)$ and 250 individuals for clams $(2 \times 250=500)$. Oyster bags were attached to an iron table, whereas clam bags were directly placed in the sediment. Sediment was collected next to the clams in October at each level in triplicate to evaluate the bacterial community.

An initial sampling was performed just before deployment in the field. Digestive gland (DG) of oysters $(n=15)$ and clams $(n=15)$ were sampled in RNase-DNase free conditions. Dissected DG were rinsed using sterilized filtered $(0.22 \mu \mathrm{m})$ and autoclaved seawater and were frozen in liquid nitrogen before being stored separately in cryotubes at $-80^{\circ} \mathrm{C}$. Sediments were collected next to the clams in October at each level in triplicate to evaluate the bacterial community.

In February 2018, oysters and clams were removed from the three intertidal levels over three consecutive days at spring low tides (31/01, 01/02 and 02/02). For each level, collected animals were either directly dissected ( $\mathrm{n}=15$; clams $19.6 \pm 3.4 \mathrm{~mm}$; oysters $49.1 \pm 7.1 \mathrm{~mm}$ ) or brought to the laboratory to be placed in depuration ( $n=15$; clams $18.9 \pm 4.1 \mathrm{~mm}$; oysters $45.7 \pm 5.7 \mathrm{~mm}$ ). In the present study, the purpose of depuration was to empty the digestive glands and to reduce the environmental microorganisms (Romero et al. 2002; Lee et al. 2008), in order to evaluate the persistence of environmental conditioning on bivalve DG microbiota.

Depurated oysters and clams were grouped by sampling day in a bag and placed for 14 days in $30 \mathrm{~L}-$ tanks (one by intertidal level) containing filtered seawater (10- and $5-\mu \mathrm{m}$ sand filters and UV treatment before two $1-\mu \mathrm{m}$ filters and a second UV treatment) renewed at $3 \mathrm{~L}$ minutes ${ }^{-1}$. Temperature of seawater in tanks was similar to temperature variations of the natural seawater. Tanks were cleaned every second day to avoid biofilm formation and no feed was added. Sediments (25g on triplicate) were collected at each level, while seawater was sampled ( $1 \mathrm{~L}$ in triplicate) 2 hours before low tide, close to animals. Sediments collected next to clams were directly stored at $-80^{\circ} \mathrm{C}$, while the seawater samples were successively passed through 8and $0.22-\mu \mathrm{m}$ polycarbonate filters (Whatman, USA), before being stored at $-80^{\circ} \mathrm{C}$ until DNA extraction. During this period, no mortality events occurred for both bivalves, no brown ring disease nor Vibrio tapetis were detected in clams, suggesting that this study was realized on healthy bivalves.

\section{DNA extraction}

The extraction of bacterial genomic DNA (gDNA) from the DG of oysters and clams combined the use of phenol-chloroform-isoamyl alcohol (PCI) extraction with a DNA extraction kit (PowerLyser Powersoil DNA Isolation, Qiagen, USA). Briefly, after homogenization of the DG, $40 \mathrm{mg}$ were collected to be digested at $45^{\circ} \mathrm{C}$ 
for 30 minutes in a lysis buffer $(178 \mu \mathrm{L})$ consisting in TNE (Tris- $\mathrm{HCl} 1 \mathrm{M}$ at $\mathrm{pH} 8, \mathrm{NaCl} 5 \mathrm{M}$, EDTA 0.5M at pH 8), SDS $20 \%$ and proteinase $\mathrm{K}\left(20 \mathrm{mg} \mathrm{mL}^{-1}\right.$ ). After centrifugation (10 $\mathrm{min}, 10,000 \mathrm{~g}$ ), supernatant was recovered and stored at $4^{\circ} \mathrm{C}$. A second digestion was carried out on the pellet by adding $100 \mu \mathrm{L}$ of lysis buffer at $45^{\circ} \mathrm{C}$ for 1 hour. After centrifugation (10 $\mathrm{min}, 10,000 \mathrm{~g}$ ) the recovered digestate was then pooled with the first one. This digestion product $(200 \mu \mathrm{L})$ was then mechanically lysed in PowerBead tubes $(0.1 \mathrm{~mm})$ from the Powerlyser kit, to which Beads $(650 \mu \mathrm{L})$ and the $\mathrm{C} 1$ solution $(60 \mu \mathrm{L})$ were added, before being shaken in the FastPrep24TM ( $2 \times 45$ seconds). Supernatant $(750 \mu \mathrm{L})$ was transferred to a new tube. One volume of phenolchloroform- isoamyl alcohol (25:24:1) was added. After mixing (45 sec) and centrifugation (15 min, 16,000 g at $4^{\circ} \mathrm{C}$ ), 1 vol of chloroform was added to the supernatant, mixed again (45 sec) and centrifuged (15 min, $16,000 \mathrm{~g}$ at $\left.4^{\circ} \mathrm{C}\right)$. Isopropanol $\left(0.7 \mathrm{vol},-20^{\circ} \mathrm{C}\right)$ was added to the supernatant to precipitate DNA. The tubes were placed overnight at $-20^{\circ} \mathrm{C}$. Precipitated DNA was centrifuged (30 min, 16,000 g at $4^{\circ} \mathrm{C}$ ). Pellet was solubilized in $500 \mu \mathrm{L}$ of TNE buffer and PowerLyser Powersoil DNA Isolation kit was used according to manufacturer's protocol. Finally, DNA was precipitated by centrifugation (30 sec, 10,000 g at room temperature), eluted in $100 \mu \mathrm{L}$ ultra-pure water (Gentrox, UK) and stored at $-80^{\circ} \mathrm{C}$.

gDNA from sediment samples (250 mg) was extracted using PowerLyser Powersoil DNA Isolation kit (Qiagen, USA), exclusively, according to the manufacturer's instructions. gDNA from seawater filters $(0.22 \mu \mathrm{m}$ and $8 \mu \mathrm{m}$ ) were extracted using $\mathrm{PCl}$ extraction according the same steps used for tissue samples as described above. After precipitation, DNA was washed with ethanol $75 \%(500 \mu \mathrm{L})$ and dried before being hydrated with $100 \mu \mathrm{L}$ ultra-pure water (Gentrox, UK).

To check for bacterial contamination of reagents, additional blank extractions were included. gDNA concentrations from tissues and environmental samples were determined by spectrofluorometric quantification using Quantifluor kit (Promega, USA) according to manufacturer's protocol.

\section{Microbiota analyses}

For each sample, 16S rRNA amplicon libraries were generated using the 341F (5'CCTACGGGNGGCWGCAG -3') and 805R (5'-GACTACHVGGGTATCTAATCC-3') primers targeting the variable V3V4 region (Herlemann et al. 2011). Paired-end sequencing with a 300-pb read length was performed at McGill University (Génome Quebec Innovation Centre, Montréal, Qc, Canada) on a MiSeq system (Illumina).

The sequencing data obtained were processed via the FROGS pipeline (Find Rapidly OTU with Galaxy Solution, v2.0.0) developed in the Galaxy environment (http: //sigenae-workbench.toulouse.inra.fr/galaxy/). This pipeline groups sequences by similarities into OTUs (Operational Taxonomic Units) and calculates taxonomic affiliations (Escudié et al. 2018). Briefly, the "pre-process" step allowed to join the paired ended reads together using FLASH with a mismatch of 0.1 (Magoč and Salzberg 2011) and to remove both primers 
and adapters using cutadapt (Martin 2011). A de novo clustering was carried out using the SWARM method, which groups the sequences into clusters from a local clustering threshold with an aggregation distance $d=3$ (Mahé et al. 2014). Chimeras were removed using VSEARCH, a method dividing each sequence into four fragments and then searching for possible parent sequences in all OTUs (Rognes et al. 2016). An abundance filter with an optimal threshold of $0.005 \%$ was applied on OTUs (Bokulich et al. 2013), except for $\alpha$-diversity. Finally, the OTUs were assigned using Blast+ and the Silva 132165 database containing known sequences of bacterial 16S rRNA. The multi-affiliated sequences were corrected by indicating for each of them an affiliation at a higher taxonomic rank. A phylogenetic tree of the OTUs and a table of abundances of affiliated OTUs were then produced in the standard BIOM format.

\section{Statistical analyses}

Niche-wise (oyster, clam, sediment, seawater fractions) microbial communities $\alpha$-diversity was assessed at the OTU level after assigning OTUs to the lowest possible taxonomic level using Simpson's inverse and Shannon entropy. Indices were computed for each individual bivalve microbiota and KruskalWallis tests were used to investigate mean differences between experimental conditions (ecological niche, sampling period, depuration impact, intertidal level effect and sampling day).

Variation in microbiota composition and structure between individual bivalves, $\beta$-diversity, was first visualized with principal component analysis (PCA) of Hellinger transformed OTU abundances. The Hellinger transformation does not give excessive weight to rare categories and may therefore help to overcome differences in sequencing depth (Legendre and Gallagher 2001). The effects of ecological niche, sampling period, depuration, intertidal level and sampling day (and their interactions) were tested using permanova (McArdle and Anderson 2001). Homogeneity of multivariate dispersion to group medoid was first assessed in order to satisfy assumptions.

To assess whether presence/absence based $\beta$-diversity in DG microbiota between tidal levels was predominantly driven by changes in species identity or fluctuations in species richness, Jaccard dissimilarity between each pair of samples was partitioned in species replacement ( $\left.\beta_{\text {Replacement }}\right)$ and richness difference ( $\beta_{\text {RichDiff }}$ ) following protocols described by Legendre 2014. Calculation and decomposition of the Jaccard dissimilarity was performed for each DG microbiota from non-depurated or depurated clams (separately), between levels (pairwise comparisons). Venn diagrams based on the Jaccard dissimilarity (presence/absence of OTUs) gave access to shared or specific OTUs of the different intertidal levels. All analyses were carried out using R3.5.2 (Team 2018), with all $\beta$-diversity analysis conducted with functions from the vegan package (Oksanen et al. 2019). 


\section{RESULTS}

\section{Data analysis information}

A total of 3,193,963 sequences were kept from all samples $(n=245)$ after processing via the FROGS pipeline (Supplementary Data). These sequences represented about $51 \%$ of all reads sequenced from the V3V4 hypervariable region of the 16S rRNA gene. The average Quality Score of amplicons was 33 (Sogin et al. 2006). After removing clusters representing less than $0.005 \%$ of all sequences, the swarm clustering produced 1,322 different OTUs divided into seawater fractions (987 OTUs), sediments (705 OTUs), DG of oysters (1129 OTUs) and clams (1197 OTUs).

\section{$\alpha$-diversity of OTUs from bivalve DG and their environment}

The number of most abundant OTUs was higher in DG than in seawater or sediments. Shannon and inverse Simpson's indices (Supplementary Table 1) indicated that total bacterial diversity (considering singletons and rare OTUs) was lower in the DG of both bivalve species (Kruskal Wallis, Shannon: d.f. $=3 ; p=$ 9.65e-13 and Simpson's inverse: d.f. $=3 ; p=4.20 \mathrm{e}-08$ ) compared to their immediate environment (Supplementary Figure 1). Bivalve digestive microbiota were dominated by few OTUs accounting for the majority of reads, whereas rare OTUs were determinant for structuring bacterial community composition of environmental samples. The implantation on the intertidal zone led to a significant increase of both $\alpha$ diversity indices (Kruskal Wallis, $p<0.001$ ) for oysters and clams. Depuration significantly reduced the $\alpha$ diversity of clams DG microbiota (Kruskal Wallis, Shannon: d.f. $=1 ; p=2.53 \mathrm{e}-11$ and Simpson's inverse: d.f. = $1 ; p=7.68 \mathrm{e}-05)$. In depurated oysters, only the Shannon index was significantly reduced, indicating a loss of rare OTUs. On the other hand, whatever indices, $\alpha$-diversity were not impacted by intertidal position for both bivalve species.

\section{Microbiota specific structure according to the host ecological niche}

Principal component analysis (PCA) of the Hellinger-transformed abundances (Fig.2) identified a separation of microbiota which were significantly different between sample types (permanova test, $R^{2}=27 \%$, $F=30.28, p=0.001$ ), in terms of both OTUs richness and relative abundances (Fig. 3). Bacterial community composition was represented on two principal component (PC) axes, separating DG microbiota of bivalve species on PC1 (15.2\%) and environmental from animal samples on PC2 (10.4\%). PCA showed that environmental microbiota were closer to DG microbiota of oysters compared to that of clams. The observed patterns were mostly associated to the contribution of OTUs affiliated to the orders of Mycoplasmatales and 
Rhodospirillales for oysters, Spirochaetales, Rickettsiales and Oceanospirillales for clams, and Rhodobacterales for environmental samples (Supplementary Figure 2). Seawater fractions appeared to be clearly separated on both axes, with the $8-0.22 \mu \mathrm{m}$ fraction closer to animals than the $>8 \mu \mathrm{m}$ fraction which was confounded with bacterial communities from sediments. Interestingly, a lower similarity of bacterial communities was established between clams DG and their closest environment, the sediment.

\section{Taxonomical composition of DG microbiota and environmental samples}

Microbiota (OTUs $>0.5 \%$ of total sequences), whatever from bivalve or environmental samples, were dominated by 8 phyla, Proteobacteria, Tenericutes, Actinobacteria, Spirochaetae, Chlamydiae, Fusobacteria, Bacteroidetes and Planctomycetes (Fig. 3). Before implantation in the field in October, oyster DG microbiota were mainly dominated by Mycoplasmatales (87\%), while Mycoplasmatales (43\%), Chlamydiales (23\%), Rickettsiales (21\%) and Spirochaetales (10\%) were dominant in clams. After 4 months of implantation in the intertidal zone, the DG microbiota diversity of both bivalves was significantly modified (Fig.4). Indeed, the relative abundance of Mycoplasmatales decreased in non-depurated oysters, while that of Rhodospirillales and Campylobacterales increased. Moreover, Chlamydiales, Legionellales and Planctomycetales were detected in February but not in October. The same trend was observed in clams, with a decreased abundance of Mycoplasmatales and Chlamydiales in February compared to October in favor of Rickettsiales, Spirochaetales and Oceanospirillales as well as, to a lesser extent, Legionellales, Corynebacteriales and Planctomycetales. Bacterial communities from bivalves DG microbiota were clearly different from those in environmental samples (Fig. 3), which were mainly dominated by Desulfobacterales (36\%), Campylobacterales (30\%), Acidimicrobiales (25\%) and Fusobacteriales (7\%) for sediments, and Rhodobacterales (99\%) for the seawater small particles fraction (8-0.22 $\mu \mathrm{m})$; and Rhodobacterales $(66 \%)$, Campylobacterales (14\%), Desulfobacterales (10\%), Acidimicrobiales (5\%) and Fusobacteriales (3\%) for the large particles fraction $(>8 \mu \mathrm{m})$. This later fraction harbored several taxa similar to those found in sediments (Supplementary Data).

For both bivalves, depuration decreased the abundance of Mycoplasmatales. This decrease, in favor of Spirochaetales in clams and Chlamydiales in oysters, was associated with a decrease of less abundant OTUs, such as Desulfobacterales and Rhodobacterales in both bivalves. In non-depurated oysters, a negative correlation (Pearson correlation: $-0.34, p=0.020$ ) was observed between the three intertidal levels and relative abundance of Rhodospirillales, which were more abundant at the lowest level. In non-depurated clams, the relative abundance of Oceanospirillales was positively correlated (Pearson correlation: $0.33, p=$ 0.025) with a higher position on the intertidal zone, whereas this correlation was negative for Legionellales (Pearson correlation: $-0.39, p=0.008$ ). 


\section{Consequences of implantation on digestive microbiota and inter-individual variability}

OTU abundances from non-depurated oysters or clams highlighted two separate groups (Fig. 4) according to the sampling period (permanova test, oyster: $R^{2}=17 \%, F=11.48, p=0.001$ and clam: $R^{2}=15 \%$, $F=15.59, p=0.001)$. These results demonstrated that bivalve DG microbiota were drastically modified after three-and-a-half-month implantation in the intertidal zone. These changes in DG microbiota were mainly explained by OTUs affiliated to Mycoplasmatales and Rhodobacterales for oysters (Supplementary Figure 4A), and to Chlamydiales, Legionellales, Mycoplasmatales, Oceanospirillales, Rhodospirillales and Rickettsiales for clams (Supplementary Figure 4B). Additionally, sample dispersion, measured by average of the distances to the median, was significantly higher (ANOVA, d.f. $=1, p=2,51 \mathrm{e}-05$ ) for oysters sampled in February $(d=0,73)$ than in October $(d=0,59)$. These results reflected an increase in the inter-individual variability during implantation. Unlike oysters, clams' inter-individual variability was not modified during implantation, indicating different responses in both species.

\section{Short spatial and temporal scales as shapers of bacterial community of bivalve DG microbiota and environmental samples}

Bivalve position on the intertidal zone significantly modified their DG microbiota (Table 1). The "Sampling day" factor only affected DG microbiota composition in oysters (permanova test, $p=0.013$ ). No interaction between "level" and "sampling day" factors was observed, regardless of the species. Oysters DG microbiota were impacted both by short spatial and temporal scales, while that of clams was only impacted by the position on the intertidal zone. Bacterial communities from sediments differed significantly regarding the intertidal level (permanova test, $p=0.001$ ). Bacterial community found in the $8-0.22 \mu \mathrm{m}$ seawater fraction was the only water fraction impacted by the sampling day (permanova test, $p=0.01$ ).

In order to evaluate the persistence of intertidal level impact on bivalve DG microbiota, oysters and clams were placed in controlled laboratory conditions for depuration. After 14 days of depuration, significant dissimilarities were observed between DG microbiota of depurated and non-depurated bivalves for both species (Supplementary Figure 5). Moreover, depuration induced an increase of the inter-individual variability in both species, compared to non-depurated bivalves (ANOVA, oysters: d.f. $=1, p=1.624 \mathrm{e}-10$ and clams: d.f. $=1, p=0.017)$. Both species DG microbiota were still significantly impacted after depuration by their intertidal levels (Table 1). Moreover, even if the sampling day did not significantly impact oysters DG microbiota after depuration, this factor significantly interacted with the intertidal levels factor (permanova test, $p=0.005)$, suggesting that oysters DG microbiota were fairly unstable from one day to the next. 


\section{Decomposition of OTU variations in DG microbiota of clams placed at three different intertidal levels}

Calculation and decomposition of the Jaccard dissimilarity between the three intertidal levels provided information on the percentage of inter-level similarity (Fig. 5). Inter-levels comparisons highlighted that nondepurated clams DG microbiota shared on average $25 \%$ of their OTUs between the three levels (Fig. $5 \mathrm{~A}$ ), with the most pairwise similarities lying between $20 \%$ and $40 \%$ of shared OTUs. For all level comparisons, dissimilarities between clams DG microbiota were mainly the consequence of OTU replacement (43\%-48\%), while richness difference ranged from $26 \%$ to $32 \%$. Compared to similarity, values of the two dissimilarity components were much less uniform, with replacement and difference richness lying respectively between $10 \%-75 \%$ and $5 \%-80 \%$. If dissimilarity seemed to be distributed in a consistent manner in high-middle and low-middle level comparisons, replacement was higher (48\% vs $43 \%$ ) and richness difference lower ( $27 \%$ vs 33\%) for high-low level comparison. These results indicated a global microbiota composition shifting (led by OTUs replacement) between DG microbiota from clams placed on these two extreme levels.

Comparatively to non-depurated clams, depuration led to a drastically decrease of richness difference (19\% on average) for all inter-level comparisons, while similarity ( $22 \%$ on average) was also reduced by $3 \%$ (Fig. 5B). These richness-difference and similarity decrease were offset by a higher replacement (59\% on average), indicating that some OTUs were removed and that depurated clams DG microbiota were more homogeneous in term of OTUs numbers. Compared to non-depurated bivalves, amplitudes of pairwise comparison values (for all intertidal levels comparisons) of both replacement and richness difference were lower, ranging respectively between $25 \%-80 \%$ and $5 \%-60 \%$. This lower amplitude of pairwise comparisons induced by depuration highlighted that dissimilarities of DG microbiota between intertidal levels were mainly explained by a replacement of OTUs rather than a richness difference.

\section{Identification of shared and specific OTUs among clams DG microbiota according to their intertidal level}

Non-depurated clams from the all three intertidal levels shared a total of 737 common OTUs out of 1102 identified (Fig. 6A and Supplementary Material). These common OTUs were mainly affiliated to the orders Planctomycetales (13\%), Legionellales (9\%) and Rhodobacterales (8\%), with the most abundant OTU affiliated to the Mycoplasmataceae family, representing $11 \%$ of total sequences. Clams from the high and middle levels shared the highest number of OTUs (110) compared to high-low (66) and middle-low (32) levels. For level-specific OTUs, clams placed on high and middle intertidal levels exhibited respectively 68 and 63 specific OTUs. OTUs specifically found in clams placed on the high level were affiliated to the orders Flavobacteriales (18\%) and Rhodobacterales (15\%), while those from the middle level were affiliated to the 
orders Planctomycetales (16\%) and Rhodobacterales (8\%). By contrast, only 23 OTUs were specific to clams placed on the low intertidal level and were dominated by Planctomycetales (12\%).

Depuration led to a major overhaul of the specific and common clams DG microbiota (Fig. 6B). Compared to non-depurated clams, depuration decreased by $42 \%$ the number of total identified OTUs (636). Common OTUs (240) were mainly affiliated to Legionellales (16\%), Chlamydiales (11\%), Rickettsiales (7\%) with the most abundant OTU affiliated to the Spirochaetaceae family representing $19 \%$ of total sequences. Nevertheless, the general pattern remained the same as for non-depurated clams, with DG microbiota originating from high and middle levels sharing the highest number of OTUs (88), and DG microbiota from low intertidal level showing the lowest number of specific OTUs (55), which were mainly affiliated to Flavobacteriales (15\%) and Planctomycetales (15\%). Clams from the high-low and middle-low levels shared respectively 44 and 37 OTUs. Clams placed on high and middle intertidal levels exhibited respectively 91 and 81 specific OTUs, those placed on the high level were dominated by Rhodobacterales (16\%) and Planctomycetales (11\%), while those from the middle level were mainly affiliated to Planctomycetales (12\%). At the same time both absolute and proportional values of level-specific OTUs increased for all intertidal levels after depuration compared to non-depurated clams (high: $6 \%$ to $14 \%$, middle: $6 \%$ to $12 \%$ and low: $2 \%$ to $9 \%)$. In that respect, the depuration emphasized clams DG microbiota differences observed between the three intertidal levels.

\section{DISCUSSION}

In the present study, we investigated the structuration of the DG microbiota of the Pacific oyster $C$. gigas and the Manilla clam R. philippinarum, in response to their location on the intertidal zone during a three-and-a-half-months period (October 2017 to February 2018). We found that location on the intertidal zone shaped DG microbiota of both bivalve species, in terms of taxonomical composition and structuration. The footprint of the intertidal position on bivalve DG microbiota persisted after depuration at the laboratory. The DG microbiota of oysters were unstable and fluctuated on a daily basis, while that of clams appeared to be more stable in the short-term.

\section{DG microbiota specificity depends on its ecological niche}

OTUs present in the DG microbiota of oysters were mainly associated to the orders Mycoplasmatales, Rhodospirillales, Campylobacterales and Chlamydiales, while those of clams were associated to Mycoplasmatales, Chlamydiales, Rickettsiales, Spirochaetales and Oceanospirillales. These taxa, including the predominance of Mycoplasmatales, are commonly described in oysters (King et al. 2012; Lokmer et al. 2016b) and clams (Milan et al. 2018) DG microbiota, as well as in the gut of other invertebrates (Tanaka et al. 
2004; Meziti et al. 2010; Hollants et al. 2011; King et al. 2012; Cleary et al. 2015). Bacteria assigned to the Spirochaetales order have often been associated to the crystalline style of bivalves (Bernard 1970), whereas Chlamydiales and Rickettsiales are known as intracellular bacteria found in digestive cells of oysters and clams (Harshbarger and Chang 1977; Fryer and Lannan 1994). OTUs belonging to the orders Mycoplasmatales and Rickettsiales, and OTUs assigned to the family Spirochaetaceae, were recently identified as core members of the Manila clam and Pacific oyster microbiota, respectively (Milan et al. 2018; King et al. 2020). Although large intra-species differences for relative abundances of different taxa have previously been described in bivalves, mostly associated to location, age and sampling period, microbiome host-specificity is widely accepted (Pierce and Ward 2018).

As in all filter feeding bivalves, DG of these two bivalve species are indirectly linked to their surrounding environment (seawater, sediment) through the gills that pump water into the pallial cavity to capture, process and transport food particles (Rosa et al. 2018). Nevertheless, DG microbiota of both bivalves were clearly different from the bacterial communities of sediments and seawater, confirming the existence of a gut-specific microbiota in clams (Meisterhans et al. 2015; Milan et al. 2018) and oysters (Lokmer et al. 2016b; Vezzulli et al. 2018; Dubé et al. 2019). The majority of microorganisms present in seawater were affiliated to the orders Rhodobacterales, Campylobacterales, and Desulfobacterales previously found in seawater from the Atlantic ocean (Celikkol-Aydin et al. 2016; Papadatou and Harder 2016). Bacterial communities from the two seawater fractions presented dissimilarities that could be linked to the presence of free-living bacteria in one fraction $(0.22-8 \mu \mathrm{m}$ fraction) and particle associated bacteria in the second one (> $8 \mu \mathrm{m})$ as previously described by Milici et al. (2017). This later fraction (> $8 \mu \mathrm{m})$ showed a high similarity with sediment bacterial communities, suggesting a sinking capability of the bigger particles which may be also found on the seabed. Bacterial communities from environmental samples, including sediments and water; and more specifically the $0.22-8 \mu \mathrm{m}$ seawater fraction, were closest from oyster DG microbiota than clams. This is probably the result of the differences in feeding behavior between oysters and clams, an important factor that can contribute to specific microbial differences across bivalve species (Murphy et al. 2019). Oysters filter particulate matter from pelagic zone, while clams use two siphons to ingest deposition (Rosa et al. 2018). Despite the absence of a clear trend in the composition of major taxa, several OTUs belonging to the major orders observed in oysters such as Mycoplasmatales (genus Mycoplasma), Campylobacterales (genus Arcobacter), and Planctomycetales (genera Blastopirellula and Singulisphaera) were also present in the water fraction (0.22-8 $\mu \mathrm{m}$ fraction). This proximity suggests that oysters may have preferentially fed on small particles during the sampling period, as previously described by Wisely and Reid (1978) where they identified an optimal particle ingestion size $(<5 \mu \mathrm{m})$ in the oyster Saccostrea glomerata. The daily changes in seawater bacterial community $(0.22-8 \mu \mathrm{m}$ fraction) were previously observed and 
expected here (Yung et al. 2016). Similarities between the oysters DG and seawater (0.22-8 $\mu \mathrm{m}$ fraction) bacterial communities, suggest a direct relationship between environmental changes (mostly seawater) and oysters DG microbiota. Lokmer et al. (2016a) previously showed the impact of short-term environmental fluctuations on oysters hemolymph microbiota. This study emphasizes this point showing the same tendency for the DG, an external tissue, which is more likely to reflect short-term environmental fluctuations.

Clams DG microbiota and their surrounding environment exhibited low similarities, especially for sediments, which were closer to oysters DG microbiota. OTUs present in the sediments belonged to the orders Desulfobacterales (Desulfosarcina, Desulfobulbus, Desulfococcus, Desulforhapalus, Desulfovibrio) and Campylobacterales (Sulfurovum, Sulfurimonas, Arcobacter) that are common sulphure cycle-associated bacteria present in marine sediments (de Wit 2008; Colin et al. 2013). Acidimicrobiales are generally observed in marine sediments with low salinity (Wu et al. 2009), and Fusobacteriales (Psychrilyobacter \& Propionigenium) are involved in denitrification processes (Otte et al. 2019). Oysters possess a higher filtration rate $\left(3.92 \mu \mathrm{g}\right.$ carbon consumed $\left.\mathrm{L}^{-1} \mathrm{~g}^{-1}\right)$ than clams $\left(3.03 \mu \mathrm{g}\right.$ carbon consumed $\left.\mathrm{L}^{-1} \mathrm{~g}^{-1}\right)$ with a lower trophic efficiency (18.38\% for oysters and $23.69 \%$ for clams) (Tenore, Goldman and Clarner 1973). This suggests that oysters ingested more bacteria from the environment than clams, and that the transit of these microorganisms through the digestive gland was therefore more important.

\section{Spatial trends for non-depurated DG microbiota}

The 3.5 months spent on the intertidal zone led to significant and differential changes in the DG microbiota of both bivalves, confirming that they were highly influenced by site of implantation, as already observed in oysters (Clerissi et al. 2018). However, in this study, microbiota of oysters DG seemed to be highly sensitive to small-scale environmental fluctuations, whereas that of clams was more stable at the same scale of observation. Implantation on the intertidal zone led to an increase of inter-individual heterogeneity of DG microbiota in non-depurated oysters but not in clams. This may be explained either by a different environmental impact on each individual due to genetics (Wegner et al. 2013; Clerissi et al. 2018) and/or the presence of micro-environmental heterogeneity (Lokmer et al. 2016a). The different intertidal positions, localized within a small area, impacted the relative abundance of major OTUs of DG microbiota, with a predominance of OTUs related to Rhodospirillales and Legionellales orders for oysters and clams, respectively, placed at the low level on the intertidal zone. Previous studies have shown that the oyster microbiota are influenced by large and small spatial location $(<1 \mathrm{~m})$, engendering heterogeneity in microbial composition (Wegner et al. 2013; Lokmer et al. 2016a; King et al. 2019a). 


\section{Environmental footprint on depurated DG microbiota}

In order to evaluate how deeply the implantation in different intertidal positions influenced their DG microbiota, bivalves were placed in depuration for 14 days without feeding. Mostly, depuration is used to remove environmental contaminants such as microplastics (Paul-Pont et al. 2016), heavy-metal (Freitas et al. 2012) or human pathogens (El-Shenawy 2004), during a short period (few hours) (Vezzulli et al. 2018). In the present study, it was used to empty the DG and to reduce transient environmental microorganisms (Romero et al. 2002; Lee et al. 2008).

The $\alpha$-diversity of the DG microbiota was reduced in clams and oysters following depuration, and a restructuring of OTU abundances was observed, as it was highlighted in oysters and mussels tissues (Lokmer et al. 2016a; Vezzulli et al. 2018). These modifications were probably related to the new environmental niches made available for other bacteria following depuration. Depuration also induced a drastic OTU reduction, which mostly affected OTUs common to all the three levels, leading to a strong increase in levelspecific OTUs for clams, and inter-individual variability for both species. In oysters, the intertidal position effect observed after depuration was in interaction with the sampling day, supporting the hypothesis that oysters DG microbiota were susceptible to seawater variations on a daily basis.

For clams, persistence of intertidal position effect on depurated animals could be related to bacteria closely associated to the clams DG. This environmental footprint coupled with the increase of level-specific OTUs (belonging to Rhodobacterales, Planctomycetales and Flavobacteriales), suggest the existence of autochthonous bacteria in clams DG microbiota. The notion of autochthonous and allochthonous microorganisms has already been evocated for the hemolymph microbiota of Pacific oysters, where seawater-associated OTUs are transient within the microbial community (Lokmer and Wegner 2014). Based on similarities comparisons between depurated or non-depurated clams placed on the three intertidal levels, autochthonous bacteria of the DG represented around $20 \%$ of bacteria present in the microbiota. Although it has not been possible yet to make a clear distinction between non-native and indigenous microorganisms in bivalves (King et al. 2012), microbiota associated with clams internal organs, may have been made up of indigenous populations despite the strong environmental influence (Meisterhans et al. 2015).

\section{CONCLUSION}

The present study confirmed that the DG bacterial microbiota of the Pacific oyster and the Manilla clam clearly differed from their surrounding environments. It highlighted that small differences in the spatial distribution of oysters and clams, along the intertidal zone, induced significant changes in their DG bacterial microbiota after three-and-a-half-month of winter implantation. We currently do not know whether these 
changes, which persisted after 14 days of depuration, were likely to affect the nutrient absorption capacity or other physiological traits of the two bivalves. While the DG microbiota of oysters were unstable and fluctuated on a daily basis, that of clams seemed to be more stable in the short-term, suggesting a better ability to regulate its DG microbiota. The depuration process revealed the presence of $20 \%$ identical OTUs shared among the three intertidal levels in clams. The exact roles of these resident bacteria on clams physiology are currently unknown, but they may play a key role by maintaining specific metabolic functions within the DG bacterial microbiota that was otherwise subjected to a wide influence of transient bacteria.

\section{SUPPLEMENTARY DATA}

Supplementary data are available at FEMSEC online.

\section{AUTHOR CONTRIBUTIONS}

Experiments, microbiota analyses, results interpretation, writing-original draft preparation, C.O.; microbiota analyses, results interpretation, S.P.; Experiment preparations, K.C.; Expertise for statistical analyses, O.G.; Project and experimental design, oyster and clam dissections, A.B., P.M., B.P., C.C., F.P., C.F., and C.P.; Project supervision and experimental design, field monitoring, oyster and clam dissections, results interpretation, writing-review and funding acquisition, G.L.B.

\section{FUNDINGS}

This work was supported by ISblue project, Interdisciplinary graduate school for the blue planet (ANR-17EURE-0015) and co-funded by a grant from the French government under the program "Investissements d'Avenir". The Region Bretagne SAD (2017, "Stratégie d'Attractivité Durable") contributed to this study through postdoctoral fellowship of Clément Offret. This work was also supported by the HORIZON2020 project "Preventing and mitigating farmed bivalve disease-VIVALDI (grant number 678589)". 


\section{ACKNOWLEDGMENTS}

The authors wish to thank Elodie Fleury, Christophe Lambert, Nelly Le Goic, Morgan Perennou, Christine Dubreuil, Valérian Le Roy, Claudie Quere, Amélie Segarra, Alexandra Rahmani, Elyne Dugény, Morgan Smith, Lizenn Delisle, Véronique Loiseau and Amandine Morot for their help with sampling preparation and dissections of bivalves, and Dominique Hervio for her help with water filtration.

Conflict of Interest. The authors declare that the research was conducted in the absence of any commercial or financial relationships that could be construed as a potential conflict of interest.

\section{REFERENCES}

Baker DM, Freeman CJ, Wong JCY et al. Climate change promotes parasitism in a coral symbiosis. ISME J 2018;12:921-30.

Barnes RD, Ruppert EE. Invertebrate Zoology. Fort Worth [Tex.: Saunders College Pub., 1996.

Bernard FR. Occurrence of the spirochaete genus Cristispira in western Canadian marine bivalves. Veliger 1970;13:33-36.

Bokulich NA, Subramanian S, Faith JJ et al. Quality-filtering vastly improves diversity estimates from Illumina amplicon sequencing. Nature Methods 2013;10:57-9.

Celikkol-Aydin S, Gaylarde CC, Lee T et al. 16S rRNA gene profiling of planktonic and biofilm microbial populations in the Gulf of Guinea using Illumina NGS. Marine Environmental Research 2016;122:105-12.

Cleary DFR, Becking LE, Polónia ARM et al. Composition and predicted functional ecology of musselassociated bacteria in Indonesian marine lakes. Antonie Van Leeuwenhoek 2015;107:821-34.

Clerissi C, de Lorgeril J, Petton B et al. Diversity and stability of microbiota are key factors associated to healthy and diseased Crassostrea gigas oysters. bioRxiv 2018:378125.

Colin Y, Goñi-Urriza M, Caumette P et al. Combination of high throughput cultivation and dsrA sequencing for assessment of sulfate-reducing bacteria diversity in sediments. FEMS Microbiol Ecol 2013;83:26-37.

Connell JH. Community interactions on marine rocky intertidal shores. Annual review of ecology and systematics 1972;3:169-192. 
Desriac F, Le Chevalier P, Brillet B et al. Exploring the hologenome concept in marine bivalvia: haemolymph microbiota as a pertinent source of probiotics for aquaculture. FEMS Microbiology Letters 2014;350:107-16.

Dhanasiri AKS, Brunvold L, Brinchmann MF et al. Changes in the Intestinal Microbiota of Wild Atlantic cod Gadus morhua L. Upon Captive Rearing. Microb Ecol 2011;61:20-30.

Dubé CE, Ky C-L, Planes S. Microbiome of the Black-Lipped Pearl Oyster Pinctada margaritifera, a Multi-Tissue Description With Functional Profiling. Front Microbiol 2019;10, DOI: 10.3389/fmicb.2019.01548.

El-Shenawy NS. Heavy-metal and microbial depuration of the clam Ruditapes decussatus and its effect on bivalve behavior and physiology. Environmental Toxicology 2004;19:143-53.

Escudié F, Auer L, Bernard M et al. FROGS: Find, Rapidly, OTUs with Galaxy Solution. Bioinformatics 2018;34:1287-94.

Fernández-Reiriz MJ, Irisarri J, Labarta U. Flexibility of Physiological Traits Underlying Inter-Individual Growth Differences in Intertidal and Subtidal Mussels Mytilusgalloprovincialis. PLOS ONE 2016;11:e0148245.

Freitas R, Ramos Pinto L, Sampaio $\mathrm{M}$ et al. Effects of depuration on the element concentration in bivalves: Comparison between sympatric Ruditapes decussatus and Ruditapes philippinarum. Estuarine, Coastal and Shelf Science 2012;110:43-53.

Fryer JL, Lannan CN. Rickettsial and chlamydial infections of freshwater and marine fishes, bivalves, and crustaceans. Zoological studies 1994;33:95-107.

Green TJ, Barnes AC. Bacterial diversity of the digestive gland of Sydney rock oysters, Saccostrea glomerata infected with the paramyxean parasite, Marteilia sydneyi. Journal of Applied Microbiology 2010;109:613-22.

Green TJ, Siboni N, King WL et al. Simulated marine heat wave alters abundance and structure of Vibrio populations associated with the Pacific Oyster resulting in a mass mortality event. Microbial ecology 2019;77:736-747.

Hacquard S, Schadt CW. Towards a holistic understanding of the beneficial interactions across the Populus microbiome. New Phytologist 2015;205:1424-1430.

Harley CDG, Hughes AR, Hultgren KM et al. The impacts of climate change in coastal marine systems. Ecology Letters 2006;9:228-41.

Harris JM. The presence, nature, and role of gut microflora in aquatic invertebrates: A synthesis. Microb Ecol 1993;25:195-231.

Harshbarger JC, Chang SC. Chlamydiae (with phages), mycoplasmas, and richettsiae in Chesapeake Bay bivalves. Science 1977;196:666-668.

Helmuth BST, Hofmann GE. Microhabitats, Thermal Heterogeneity, and Patterns of Physiological Stress in the Rocky Intertidal Zone. The Biological Bulletin 2001;201:374-84.

Herlemann DP, Labrenz M, Jürgens K et al. Transitions in bacterial communities along the $2000 \mathrm{~km}$ salinity gradient of the Baltic Sea. ISME J 2011;5:1571-9. 
Hollants J, Leroux O, Leliaert F et al. Who Is in There? Exploration of Endophytic Bacteria within the Siphonous Green Seaweed Bryopsis (Bryopsidales, Chlorophyta). PLOS ONE 2011;6:e26458.

King GM, Judd C, Kuske CR et al. Analysis of Stomach and Gut Microbiomes of the Eastern Oyster (Crassostrea virginica) from Coastal Louisiana, USA. PLoS ONE 2012;7:e51475.

King WL, Jenkins C, Go J et al. Characterisation of the Pacific Oyster Microbiome During a Summer Mortality Event. Microb Ecol 2019a;77:502-12.

King WL, Jenkins C, Seymour JR et al. Oyster disease in a changing environment: decrypting the link between pathogen, microbiome and environment. Marine environmental research 2019b;143:124-140.

King WL, Siboni N, Kahlke T et al. Regional and oyster microenvironmental scale heterogeneity in the Pacific oyster bacterial community. FEMS Microbiol Ecol 2020;96, DOI: 10.1093/femsec/fiaa054.

King WL, Siboni N, Williams NLR et al. Variability in the Composition of Pacific Oyster Microbiomes Across Oyster Families Exhibiting Different Levels of Susceptibility to OsHV-1 $\mu$ var Disease. Front Microbiol 2019c;10, DOI: 10.3389/fmicb.2019.00473.

Kueh CSW, Chan K. Bacteria in bivalve shellfish with special reference to the oyster. Journal of Applied Bacteriology 1985;59:41-7.

Kvennefors ECE, Sampayo E, Ridgway T et al. Bacterial Communities of Two Ubiquitous Great Barrier Reef Corals Reveals Both Site- and Species-Specificity of Common Bacterial Associates. PLOS ONE 2010;5:e10401.

Lee R, Lovatelli A, Ababouch L. Bivalve Depuration: Fundamental and Practical Aspects. Food and Agriculture Organization of the United Nations, 2008.

Legendre P. Interpreting the replacement and richness difference components of beta diversity. Global Ecology and Biogeography 2014;23:1324-34.

Legendre P, Gallagher ED. Ecologically meaningful transformations for ordination of species data. Oecologia 2001;129:271-80.

Lessin G, Bruggeman J, McNeill CL et al. Time Scales of Benthic Macrofaunal Response to Pelagic Production Differ Between Major Feeding Groups. Front Mar Sci 2019;6, DOI: 10.3389/fmars.2019.00015.

Lokmer A, Goedknegt MA, Thieltges DW et al. Spatial and Temporal Dynamics of Pacific Oyster Hemolymph Microbiota across Multiple Scales. Front Microbiol 2016a;7, DOI: 10.3389/fmicb.2016.01367.

Lokmer A, Kuenzel S, Baines JF et al. The role of tissue-specific microbiota in initial establishment success of Pacific oysters. Environ Microbiol 2016b;18:970-87.

Lokmer A, Wegner KM. Hemolymph microbiome of Pacific oysters in response to temperature, temperature stress and infection. ISME J 2014;9:670-82.

Magoč T, Salzberg SL. FLASH: fast length adjustment of short reads to improve genome assemblies. Bioinformatics 2011;27:2957-63. 
Mahé F, Rognes T, Quince C et al. Swarm: robust and fast clustering method for amplicon-based studies. PeerJ 2014;2:e593.

Martin M. Cutadapt removes adapter sequences from high-throughput sequencing reads. EMBnet journal 2011;17:10-12.

McArdle BH, Anderson MJ. Fitting Multivariate Models to Community Data: A Comment on Distance-Based Redundancy Analysis. Ecology 2001;82:290-7.

McFall-Ngai M, Hadfield MG, Bosch TCG et al. Animals in a bacterial world, a new imperative for the life sciences. Proc Natl Acad Sci USA 2013;110:3229-36.

McFall-Ngai MJ. Unseen forces: the influence of bacteria on animal development. Developmental biology 2002;242:1-14.

Meisterhans G, Raymond N, Girault E et al. Structure of Manila Clam (Ruditapes philippinarum) Microbiota at the Organ Scale in Contrasting Sets of Individuals. Microb Ecol 2015:1-13.

Menzel W. Estuarine and Marine Bivalve Mollusk Culture. CRC Press, 2018.

Meziti A, Ramette A, Mente E et al. Temporal shifts of the Norway lobster (Nephrops norvegicus) gut bacterial communities. FEMS Microbiol Ecol 2010;74:472-84.

Milan M, Carraro L, Fariselli P et al. Microbiota and environmental stress: how pollution affects microbial communities in Manila clams. Aquatic Toxicology 2018;194:195-207.

Milici M, Vital M, Tomasch J et al. Diversity and community composition of particle-associated and free-living bacteria in mesopelagic and bathypelagic Southern Ocean water masses: Evidence of dispersal limitation in the Bransfield Strait. Limnology and Oceanography 2017;62:1080-95.

Murphy AE, Kolkmeyer R, Song B et al. Bioreactivity and Microbiome of Biodeposits from Filter-Feeding Bivalves. Microb Ecol 2019;77:343-57.

Offret C, Jégou C, Mounier J et al. New insights into the haemo- and coelo-microbiota with antimicrobial activities from Echinodermata and Mollusca. Journal of Applied Microbiology 2019, DOI: 10.1111/jam.14184.

Offret C, Rochard V, Laguerre H et al. Protective Efficacy of a Pseudoalteromonas Strain in European Abalone, Haliotis tuberculata, Infected with Vibrio harveyi ORM4. Probiotics Antimicrob Proteins 2018, DOI: 10.1007/s12602-018-9389-8.

Oksanen J, Blanchet FG, Friendly M et al. Vegan: Community Ecology Package., 2019.

Otte JM, Blackwell N, Ruser R et al. N2O formation by nitrite-induced (chemo)denitrification in coastal marine sediment. Sci Rep 2019;9, DOI: 10.1038/s41598-019-47172-x.

Papadatou M, Harder J. Bacterial diversity associated with anthropogenic particles and neuston in the surface layer of the East Atlantic Ocean. 2016.

Paul-Pont I, Lacroix C, González Fernández C et al. Exposure of marine mussels Mytilus spp. to polystyrene 
microplastics: Toxicity and influence on fluoranthene bioaccumulation. Environmental Pollution 2016;216:724-37.

Petton B, Boudry P, Alunno-Bruscia $\mathrm{M}$ et al. Factors influencing disease-induced mortality of Pacific oysters Crassostrea gigas. Aquaculture Environment Interactions 2015;6:205-22.

Pierce ML, Ward JE. Microbial Ecology of the Bivalvia, with an Emphasis on the Family Ostreidae. shre 2018;37:793-806.

Rognes T, Flouri T, Nichols B et al. VSEARCH: a versatile open source tool for metagenomics. PeerJ 2016;4:e2584.

Romalde JL, Diéguez AL, Doce A et al. Advances in the knowledge of the microbiota associated with clams from natural beds. Clam Fisheries and Aquaculture 2013:163-190.

Romero J, García-Varela M, Laclette JP et al. Bacterial 16S rRNA Gene Analysis Revealed That Bacteria Related to Arcobacter spp. Constitute an Abundant and Common Component of the Oyster Microbiota (Tiostrea chilensis). Microb Ecol 2002;44:365-71.

Rosa M, Ward JE, Shumway SE. Selective Capture and Ingestion of Particles by Suspension-Feeding Bivalve Molluscs: A Review. shre 2018;37:727-46.

Röszer T. The invertebrate midintestinal gland ("hepatopancreas") is an evolutionary forerunner in the integration of immunity and metabolism. Cell Tissue Res 2014;358:685-95.

Shapira M. Adaptation from Within or from Without: A Reply to Rodrigo et al. Trends in Ecology \& Evolution 2017;32:85.

Simon C, Truong H, Noble T et al. Microbial biomass, marine invertebrate meals and feed restriction influence the biological and gut microbiota response of shrimp Penaeus monodon. Aquaculture 2019:734679.

Simons AL, Churches N, Nuzhdin S. High turnover of faecal microbiome from algal feedstock experimental manipulations in the Pacific oyster ( Crassostrea gigas ). Microbial Biotechnology 2018;11:848-58.

Sogin ML, Morrison HG, Huber JA et al. Microbial diversity in the deep sea and the underexplored "rare biosphere." PNAS 2006;103:12115-20.

Soudant P, Paillard C, Choquet G et al. Impact of season and rearing site on the physiological and immunological parameters of the Manila clam Venerupis (=Tapes, =Ruditapes) philippinarum. Aquaculture 2004;229:401-18.

Tanaka R, Ootsubo M, Sawabe T et al. Biodiversity and in situ abundance of gut microflora of abalone (Haliotis discus hannai) determined by culture-independent techniques. Aquaculture 2004;241:453-63.

Team RC. R: A language and environment for statistical computing. R Foundation for Statistical Computing, Vienna, Austria. 2012. URL http://www R-project org 2018.

Tenore KR, Goldman JC, Clarner JP. The food chain dynamics of the oyster, clam, and mussel in an 
aquaculture food chain. Journal of Experimental Marine Biology and Ecology 1973;12:157-65.

Torda G, Donelson JM, Aranda M et al. Rapid adaptive responses to climate change in corals. Nature Climate Change 2017;7:627-36.

Trabal Fernández N, Mazón-Suástegui JM, Vázquez-Juárez R et al. Changes in the composition and diversity of the bacterial microbiota associated with oysters (Crassostrea corteziensis, Crassostrea gigas and Crassostrea sikamea ) during commercial production. FEMS Microbiology Ecology 2014;88:69-83.

Trabal N, Mazón-Suástegui JM, Vázquez-Juárez R et al. Molecular analysis of bacterial microbiota associated with oysters (Crassostrea gigas and Crassostrea corteziensis) in different growth phases at two cultivation sites. Microb Ecol 2012;64:555-69.

Vezzulli L, Stagnaro L, Grande C et al. Comparative 16SrDNA gene-based microbiota profiles of the Pacific oyster (Crassostrea gigas) and the Mediterranean mussel (Mytilus galloprovincialis) from a shellfish farm (Ligurian Sea, Italy). Microbial ecology 2018;75:495-504.

Wegner KM, Volkenborn N, Peter $\mathrm{H}$ et al. Disturbance induced decoupling between host genetics and composition of the associated microbiome. BMC Microbiology 2013;13:252.

Wisely B, Reid BL. Experimental feeding of Sydney rock oysters (Crassostrea commercialis = Saccostrea cucullata): I. Optimum particle sizes and concentrations. Aquaculture 1978;15:319-31.

de Wit R. Microbial diversity in the Bassin d'Arcachon coastal lagoon (SW France). Hydrobiologia 2008;611:515.

Wu J, Guan T, Jiang H et al. Diversity of Actinobacterial community in saline sediments from Yunnan and Xinjiang, China. Extremophiles 2009;13:623-32.

Yin X, Chen P, Chen $\mathrm{H}$ et al. Physiological performance of the intertidal Manila clam (Ruditapes philippinarum) to long-term daily rhythms of air exposure. Scientific Reports 2017;7:41648.

Yung C-M, Ward CS, Davis KM et al. Insensitivity of Diverse and Temporally Variable Particle-Associated Microbial Communities to Bulk Seawater Environmental Parameters. Schloss PD (ed.). Appl Environ Microbiol 2016;82:3431. 


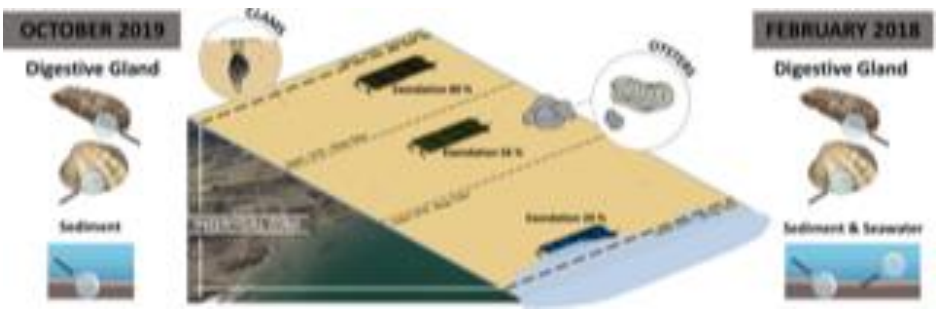

Figure 1. Representation of experimental design detailing the deployment of bivalves on the three intertidal levels (low, middle and high, corresponding to $20 \%, 56 \%$ and $80 \%$ of exondation time, respectively) and the sampling of digestive glands and environmental samples. 


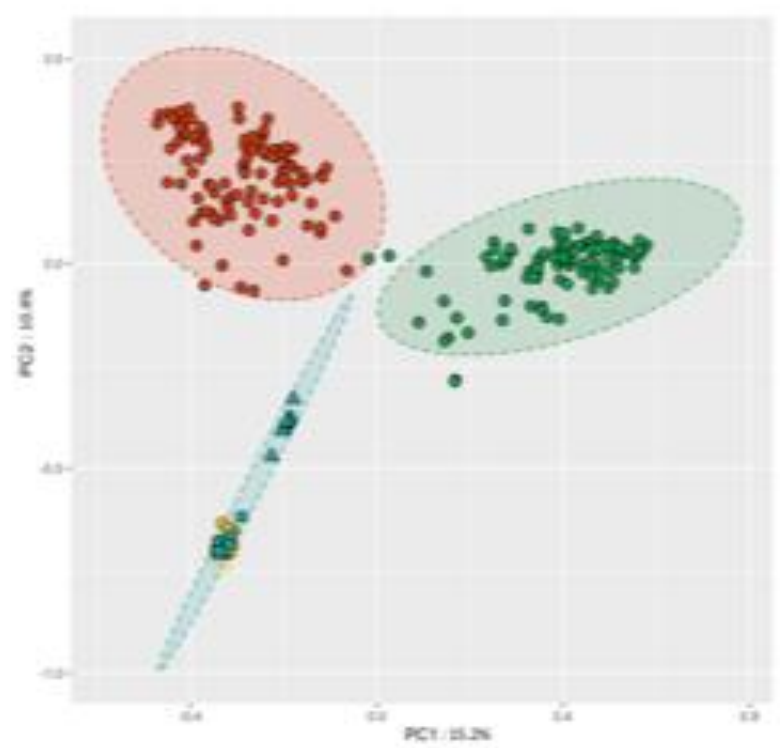

Figure 2. Principal component analysis of the Hellinger-transformed OTUs abundances for the bacterial community of sediment (yellow circles), $8 \mu \mathrm{m}$ seawater fraction (blue squares), $0.22-8 \mu \mathrm{m}$ seawater fraction (blue triangles), and DG of C. gigas (red circles) and R. philippinarum (green circles) sampled in October and February. Ellipses represent standard deviation (99\%) of data. 


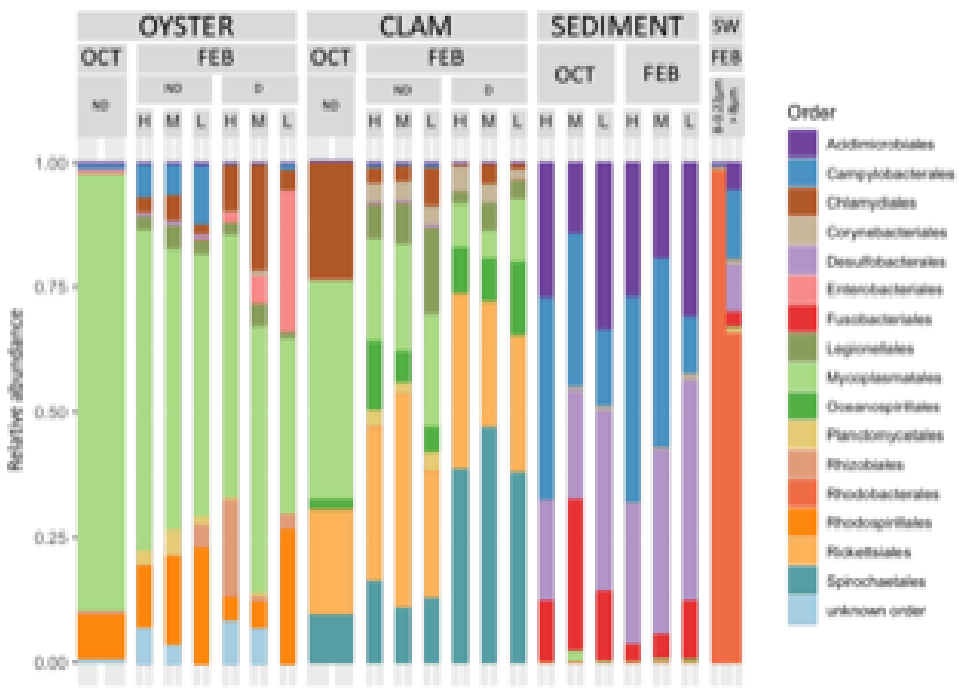

Figure 3. Relative abundance of majoritarian OTUs (OTUs representing $0.5 \%$ of total sequences) summarized at the order taxonomic rank, found in sediments, seawater (SW), and DG of C. gigas (OYSTER) and R. philippinarum (CLAM) sampled in October (OCT) or February (FEB) from non-depurated (ND) or depurated (D) animals placed at different intertidal levels $(H$, high ; $M$, middle ; L, low). 

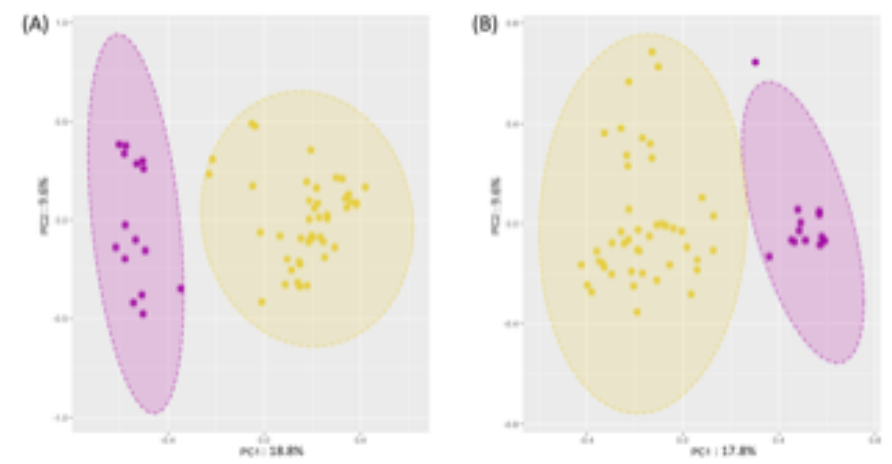

Figure 4. Principal component analysis of the Hellinger-transformed OTUs abundances for non-depurated DG bacterial communities of $C$. gigas (A) and R. philippinarum (B) sampled in October (violet) and February (yellow). The first two axes of PCA explain $28.4 \%$ and $27.4 \%$ of total variation of bacterial communities for oyster and clam respectively. Ellipses represent standard deviation (99\%) of data. 


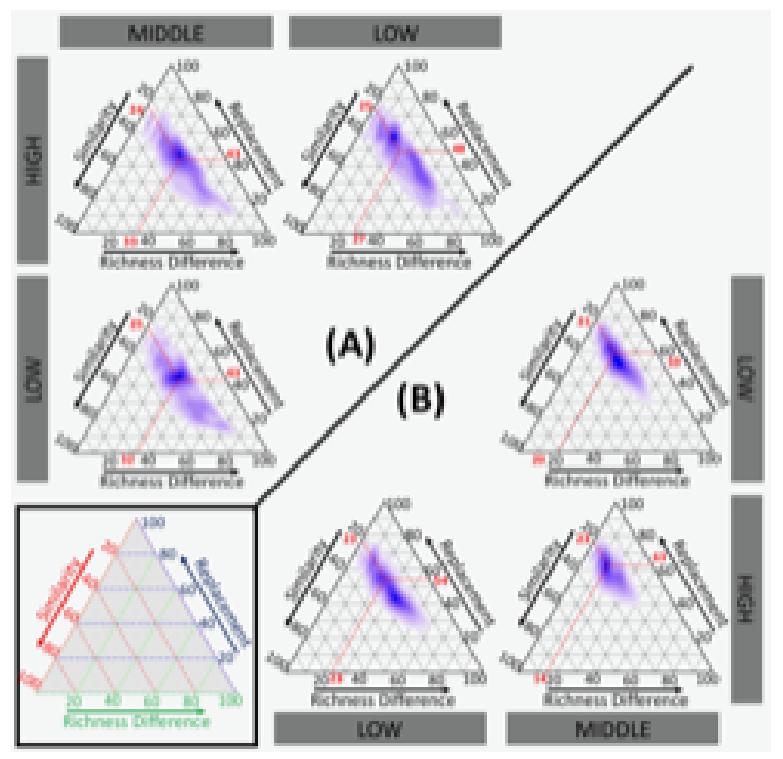

Figure 5. Triangular plots illustrating the variations of the Jaccard dissimilarity between OTU composition (presence/absence data) of non-depurated (A) and depurated (B) R. philippinarum sampled on the three intertidal levels (high, middle, low), and its decomposition into similarity, richness difference (variation in OTU richness) and OTU replacement (variation in OTU identity). Legend information are provided in the box. Contributions were calculated for each group of depurated or non-depurated animals separately, and for pairwise comparisons between each sample belonging to one level with all samples from a different level. Due to the high number of pairwise comparisons, the density of points was estimated by two-dimensional kernel estimations and was represented with dark blue for higher numbers of comparisons. Red lines indicate the centroid value for each graph with its associated mean values for the three components of dissimilarity. 


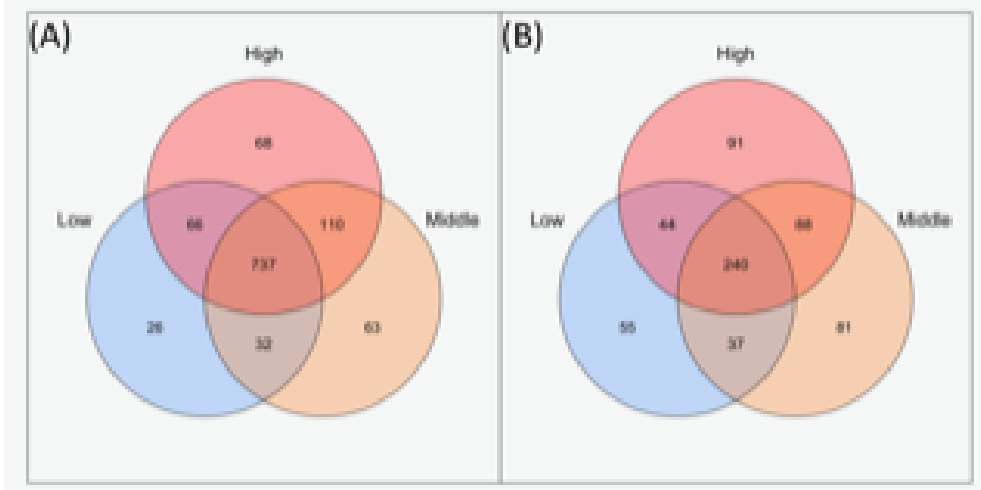

Figure 6. Venn diagrams representing shared OTUs (based on presence/absence data) between DG bacterial communities of non-depurated (A) and depurated (B) R. philippinarum that had been placed on high (red), middle (yellow) or low (blue) intertidal level. 
Table 1. $R^{2}, F$ and $p$ values obtained using a permanova to test the impact of intertidal levels ( $n=45$ by group) and sampling day ( $\mathrm{n}=15$ by group) on microbiota of bivalve's DGs. In bold significant $p$-value $(p<0.05)$.

\begin{tabular}{lcccc}
\hline Tested factors & Non-Depurated Oysters & Non-Depurated Clams & Depurated Oysters & Depurated Clams \\
\hline \multirow{2}{*}{ Levels } & $R^{2}=7.2 \%$ & $R^{2}=6.4 \%$ & $R^{2}=7.1 \%$ & $R^{2}=6.1 \%$ \\
& $F=1.70$ & $F=1.46$ & $F=1.66$ & $F=1.33$ \\
& $p=\mathbf{0 . 0 0 4 * *}$ & $p=\mathbf{0 . 0 2 6 *}$ & $p=\mathbf{0 . 0 0 1 *}$ & $p=\mathbf{0 . 0 3 3 ^ { * }}$ \\
Sampling day & $R^{2}=6.8 \%$ & $R^{2}=5.2 \%$ & $R^{2}=9.5 \%$ & $R^{2}=5.1 \%$ \\
& $F=1.61$ & $F=1.18$ & $F=0.95$ & $F=1.10$ \\
Interaction & $p=\mathbf{0 . 0 1 3 *}$ & $p=0.310$ & $p=0.904$ & $p=0.237$ \\
Levels-Sampling & $R^{2}=9.4 \%$ & $R^{2}=9.1 \%$ & $R^{2}=11.6 \%$ & $R^{2}=8.3 \%$ \\
day & $F=1.10$ & $F=1.03$ & $F=1.36$ & $F=0.90$ \\
\hline
\end{tabular}

